\title{
Possibility of oxygen-ozone therapy in the geriatric patient
}

\author{
Marianno Franzini, ${ }^{1}$ Giulia Ionita ${ }^{2}$ \\ ${ }^{1}$ President SIOOT, Professor a.c. Oxygen-Ozone therapy, University of Pavia, Pavia; ${ }^{2}$ Assistant, \\ Italy
}

\begin{abstract}
In the context of multidisciplinary care of elderly patients, this work will want to consider the presence of osteo-articular and muscular pain, mostly chronic, of these subjects. The treatment has made use of oxygen-ozone therapy, given the absence of side effects of this minimally invasive technique, and the possibility of its use simultaneously with an already established poly-drug therapy, as typically found in the geriatric patient.
\end{abstract}

\section{Introduction}

A geriatric subject is characterized by chronic, progressive, with frequent mental health problems and functional autonomy, living in harsh environments or critical, high risk of disability. He therefore presents an extreme lability homeostatic and is an extremely vulnerable body. In the elderly multidisciplinary assessment, an important issue is the presence of pain, chronic, which can greatly reduce the quality of the subject's life. Pain is an unpleasant sensation localized in a given body part. It is often described in terms of process that penetrates the tissues or damages them (e.g., stabbing pain, burning, tenebrante, tearing, constrictive) and/or physical or emotional reaction (e.g., pain that generates nausea, malaise). Any moderate or high intensity pain is also accompanied by anxiety and a desire to avoid or put an end to the painful sensation. Once you complete the diagnostic process and identified the likely causal factors and exac-

Correspondence: Marianno Franzini, Scientific Society of Oxygen-Ozone Therapy, via Roma 69 , Gorle (BG), Italy.

$\mathrm{Tel} / \mathrm{Fax}:+39.035 .300903$.

E-mail: info@ossigenoozono.it

Key words: Geriatrics; Oxygen-ozone therapy; Pain management.

Received for publication: 16 November 2016.

Accepted for publication: 13 December 2016.

CC Copyright M. Franzini and G. Ionita, 2016

Licensee PAGEPress, Italy

Ozone Therapy 2016; 1:6471

doi:10.4081/ozone.2016.6471

This article is distributed under the terms of the Creative Commons Attribution Noncommercial License (by-nc 4.0) which permits any noncommercial use, distribution, and reproduction in any medium, provided the original author(s) and source are credited. erbation of pain, you should plan a treatment. An important aspect of this process is the identification of precise and realistic therapeutic objectives such as, for example, be able to obtain an adequate patient's nocturnal rest, make it able to resume normal life activities. To improve the patient's quality of life may need a multidisciplinary approach using pharmacotherapy, a series of practical recommendations, physical therapy, nerve blocks, intraspinal cannula systems for the delivery of morphine, the intraspinal electrodes plant make stimulation of the spinal cord and, if indicated, surgery. As a new therapeutic option to check the status painful oxygen-ozone therapy is inserted as a minimally invasive technique, free from side effects and which it can be administered without interrupting other drug regimes already in place. Ozone, a powerful oxidizing administered as a mixture of oxygen-ozone, has properties such as: anti-inflammatory, analgesic, antibacterial, antiviral, immunomodulatory and improvement of microcirculation.

The mediators of pain derived from lipids (arachidonic acid, prostanoids, eicosanoids, pro-prostaglandin), protein (NGF-Nerve Growth Factor, SP, NK, CGRP), molecules by Count-nuto cytoplasmic, glutamate, potassium ions, ATP, hydrogen ions, molecules from nerve ends-tions (SP, NK, GCRP, YIP) and molecules from blood and inflamed tissue (serotonin, bradichidine). An important role in the inflammatory reaction is carried out by phospholipase A2 (for the formation of prostaglandins and leukotrienes and to the sticks to perineural and neural membranes), metalloproteinases (able will amplify the inflammatory response) and the glycoprotein YKL4 (produced abundantly later in articular lesions). Ozone improves oxygenation, inhibits activation and leukocyte adhesion, inhibits platelet activation and adhesion, inhibits the activation of phospholipase A2, cyclooxygenase and metalloproteinases. Thanks to this action is inhibited the inflammatory response bio-humoral. The ozone injection into the painful site can determine analgesic effect almost immediate because inactivates or destroys the algogenic substances (for example, by oxidation of prostaglandins), inactive bradichidine and other peptides, alters serotonin (which possesses an indole nucleus), it produces a degradation of extracellular ATP. The longlasting analgesic effect of ozone, however, occurs through denaturation of cellular proteins that produce halogen substances (such as kallikrein and kininogen), the site of alteration of the receptor algogenic substances and the increase of the expression of genes to antinociceptive activities. ${ }^{1,2}$

Treatment with ozone and then induces a rapid disappearance of joint pain and edema and a normalization of the local temperature, with increased mobility and joint function. Various diseases related to musculoskeletal system can benefit, both in the case of inflammatory events is degenerative. This is in relation to a series of concatenated effects which, starting from an improvement in the local microvasculature, causing expulsion of algogenic substances with relative de-inflammation tissue, reduction of contracture and edema, mobility recovery and then stop the pathophysiological mechanisms of degeneration. ${ }^{3}$ 


\section{Materials and Methods}

All procedures were performed in the center of oxygen-ozone therapy in Bergamo, Italy. The oxygen-ozone therapy is here studied and used for 33 years.

Ozone is generated with 95 Computerised Medical Photometric System manufactured by Multiossigen. At the end of any treatment in all patients applied the ointment is Miozon.

They were treated 64 geriatric patients since the 70 years that accused chronic pain. They were selected subjects with osteoarthritis diagnosis (25 patients) in the hands, feet, knees, hips, spine and shoulder; with diagnosis of rheumatoid arthritis (15 patients); diagnosed with fibromyalgia ( 8 patients); subjects who accused chronic muscle and joint pain without a specific diagnosis made by a specialist (16 patients).

Pain was assessed by subjective methods based on patient selfreport, to be conscious, able to self-evaluate their pain, able to understand the use of the scale and compliant. You have chosen to use the visual analogue scale (VAS), in use since 1976 in the clinical context, consisting of a line that represents a continuum of values between its ends, corresponding to the absence of pain in the strongest pain imaginable. It requires the patient to indicate the point on the line corresponding to the intensity of pain; the distance measured between the left end and the point reported by the patient corresponds to the intensity of the pain felt at that moment. ${ }^{4}$

On average, the values of the SEA reported by patients were of 8 in the case of arthrosis, 7.5 AC-know of rheumatoid arthritis, 7 in the case of fibromyalgia, 7.5 in the case of chronic muscle and joint pain (Table 1).

For treatment with oxygen-ozone have followed the protocols proposed by SIO0T, Scientific Society of Oxygen-Ozone Therapy and recommended by the ISS.

For osteoarthritis and chronic muscle and joint pain have been used average concentrations of 5 to $10 \mathrm{~g}$ of a mixture of oxygen-ozone, administered with subcutaneous maximum 5 cc injections in the painful points, applied for 10-15 sessions.

For rheumatoid arthritis oxygen-ozone was administered through great technical autohemoinfusion and subcutaneous injections. In the first case, the concentration of mixture of oxygen-ozone is of 40-50 $\mathrm{\mu g}$ (with alternation of concentrations at each session) for $200 \mathrm{cc}$ of the mixture of oxygen-ozone in $200 \mathrm{cc}$ of blood. The application provides for a cycle of 12 sessions, 1/2 per week, followed by maintenance applications every 20-30 days. In the case of subcutaneous injections, they were administered $5-10 \mathrm{cc}$ of the mixture of oxygen-ozone at a concentration of 5-10 $\mu \mathrm{g}$ in correspondence of the nodules. The cycle consists of 12 sessions, mono or bi-weekly.

For fibromyalgia, the protocol provides a cycle of 12 sessions composed by the administration by means of small autohemoinfusion (concentration of $30 \mu \mathrm{g}$ ), subcutaneous injections (concentration of $2 \mu \mathrm{g}$ ) and rectal insufflation (150 cc at a concentration of $20 \mu \mathrm{g}$ ). Additional maintenance sessions every month are planned.

\section{Results}

In all cases treated SEA average at the end of therapy was significantly decreased: in patients with osteoarthritis, from 8 to 3 ; in patients with rheumatoid arthritis, from 8.5 to 4.5 ; in patients with fibromyalgia from 7 to 2.5 ; in patients with chronic muscle pain and joint from 7.5 to 3 (Table 1).

Patients who had already taken a drug treatment for the treatment of pain declined autonomously the dose of medication, if not completely stopped drug therapy, stressing that no longer felt the need to take these medications view the progressive reduction of subjectively felt pain. The cortisone was eliminated from drug treatment schedule of patients, eliminating the risk of side effects from the use of this principle in chronic.

\section{Discussion}

Roughly, it is estimated that $48-80 \%$ of patients admitted to a longterm care facility suffering from persistent pain; however, the exact number is unknown, as well as the pain is often not recognized within care facilities, it is insufficiently substantiated or treated inappropriately. In fact, pain management within the long-term care facilities continues to be a national problem, with projections indicating that the number of hospitalized double by 2050 . In addition, many patients in these facilities commonly have more than one condition medical active, and can experience pain from multiple causes in each moment. ${ }^{5}$ not forgetting that chronic pain and depression commonly occur together. A significant clinical depression is one of the psychiatric conditions prevalent in old age, affecting more than $35 \%$ of the general population aged 60 and over. Studies on the severity of depression and secondary measures such as the patient's functional status, quality of life, costs on health and use of health care, and effectiveness of the treatments have suggested that depression has more impact than other factors on the patient. Its effects are expressed with a functional deterioration in patients with pain. ${ }^{6}$

In the literature, numerous studies have investigated the analgesic effect of ozone in the general population and, in our case, we selected the possible effects of painkillers on the geriatric population.

For example, Gjonovich et al..$^{7}$ have treated cases of shoulder pain and concluded that the ozone analgesic effect was significant in at least $77 \%$ of the treated cases, stressing that this technique, compared to mesotherapy, has demonstrated an effect with higher latency but more pronounced remotely, particular to the final control after 60 days. The authors also showed a progressive recovery of joint function, already significant after 15 days and this could be interpreted as the result of an increase in angiogenesis and local oxygenation resulting in stimulation of tissue reparative processes and improving the func-

Table 1. Values reported by patients.

\begin{tabular}{lccc} 
Diagnosis & Theated patients (n) & VAS at the beginning of treatment \\
Arthrosis & 25 & 8 & VAS at the end of treatment \\
Rheumatoid arthritis & 15 & 8.5 & 3 \\
\hline Fibromyalgia & 8 & 4.5 & 7.5 \\
Muscular and articular chronic pain & 16 & - & 3 \\
\hline Total & 64 & -
\end{tabular}

VAS, visual analogue scale. 
tionality of the muscle fibers themselves, both those that those damaged ones intact.

Still, Zanardi et al. ${ }^{8}$ have found, from a clinical point of view, an optically bad response to instances of painful metatarsalgy with complete resolution of symptoms after four sessions of oxygen-ozone therapy. The authors noted as early as after the first treatment session the benefit was significant, and that this improvement was not immediate, but found between 24 and $48 \mathrm{~h}$ after the infiltration itself. The re-search showed that the ozone is able to normalize the prostaglandin E2 levels, resulting in decreased pain and resolution of the inflammatory state.

In addition, Wong et al. ${ }^{9}$ studied 122 patients with osteoarthritis diagnosis, showing that $95 \%$ of treated cases have obtained a satisfactory response from the treatment, indicating that $72 \%$ of patients, states the disappearance of pain during 20 sessions and who did not return with these symptoms up to 2,3 or 6 months after the end of treatment. It is good to report that the ozone, for its stimulating effect or activator of cellular oxidative mechanisms, as well as the proportional increase of the fluidity of the synovial fluid, has the ability to make disappear permanently linked to the osteoarthritis pain.

Even studies on patients with fibromyalgia, still few in the literature, have shown that the use of oxygen-ozone injected in correspondence of trigger points, highlighted by deep palpation and which correspond to indurations or nodules subcutaneous tissue, have excellent therapeutic response. Borrelli et al. ${ }^{10}$ demonstrated that the 5 patients with fibromyalgia treated in their study, 4 showed a definite improvement, while only one patient did not show any improvement because of the shortage of intravenous access and that they had not accepted the 'rectal insufflation. Still, according Loconte, ${ }^{11}$ the complex variety of symptoms of fibromyalgia, the results obtained with oxygen-ozone therapy are encouraging, because they attenuate the symptoms, ensuring better quality both of the mood that sleep, improving the quality of life of patients . This finding is valid starting from histochemical and bioenergy investigations (VEGA-TEST) which showed in the subcutaneous tissue and muscle decreased $\mathrm{pO}_{2}$ with metabolic acidosis, low levels of ATP and creatine phosphate, mitochondrial oxidative stress, all the conditions on which the ozone can exert its action.

Here we remember that ozone also has a good ability immunomodulatory that positively influences the etiology of rheumatoid arthritis, justifying the positive results obtained in the treatment of affected patients.

\section{Conclusions}

The treatment with oxygen-ozone was effective in the treatment of painful conditions, including chronic and disabling, the geriatric patient. Patients treated by us are pain patients with predominant mechanical component. The oxygen-ozone therapy improves the patient's quality of life and gives back to the subject a good degree of autonomy. Moreover, as noted, with the reduction of the pain improves the mood of the patient, expect in the elderly and frail patient's context is always to be found as an objective. It should be stressed the ease of implementation, the excellent tolerability by the patient, as well as the absence of side unwanted effects. ${ }^{7}$ We expect that the technical oxygen-ozone therapy can spread between conservative therapies and be more and more chosen as analgesic method in combination with other therapeutic protocols, though not as the main treatment of pain.

\section{References}

1. Fauci AS, Kasper DL, Longo DL. [Harrison principi di medicina interna]. [Book in Italian]. 17th ed. New York: McGraw-Hill; 2008.

2. Franzini M. [Ossigeno ozono terapia che cos'è e cosa fa]. [Book in Italian]. Gorle: Edizioni SIOOT; 2014.

3. Valdenassi L, Franzini M, Richelmi P, Bertè F. [Ossigeno-ozono terapia]. In: [Atti del primo convegno della sezione SIMFER di Riabilitazione Ambulatoriale Passaggio lombo-sacrale e sacro-iliache: progetti e programmi riabilitativi multidisciplinari]. [Proceedings in Italian]. Pavia: SIMFER; 2003.

4. Caprilli S, Conversano C. [Approccio al paziente e misura del dolore]. In: [Il management del dolore nel paziente con lesioni osteoarticolari traumatiche in tutte le età della vita, prima edizione]. [Contribution in Italian]. Siena: Azienda Ospedaliera di Siena; 2010.

5. Fine PG, Bradshaw DH, Cohen MJ, et al. Evaluation of the performance improvement CME paradigm for pain management in the long-term care setting. Pain Medicine 2014:15:403-9.

6. Tarakci E, Zenginler Y, Kaya Mutlu E. Chronic pain, depression symptoms and daily living independency level among geriatrics in nursing home. Agri 2015;27:35-41.

7. Gjonovich A, Girotto L, Sattin GF, et al. [L'ossigeno-ozono terapia nella spalla dolorosa]. [Article in Italian]. Rivista Italiana di Ossigeno-Ozonoterapia 2002;1:37-40.

8. Zanardi G, Zorandi A. [Ossigeno-ozonoterapia nel trattamento della patologia dolorosa del piede d'atleta]. [Article in Italian]. Rivista Italiana di Ossigeno-Ozonoterapia 2002;1:51-6.

9. Wong R, Cellabos A, Menéndez S, Gomez M. [Ozonoterapia analgesica]. [Article in Spanish]. Revista CENIC Ciencias Biologicas 1989;20:143-50.

10. Borrelli E, Bocci V. A novel therapeutic option for chronic fatigue syndrome and fibromyalgia. Rivista Italiana di OssigenoOzonoterapia 2002;1:149-53.

11. Loconte S. [Sindrome fibromialgica primaria]. [Contribution in Italian]. In: Proceedings of the First IMOS Congress, 2-4 November 2000 , Siena, Italy. 